Review Article

\title{
A Review on the Effect of Crumb Rubber Addition to the Rheology of Crumb Rubber Modified Bitumen
}

\author{
Mohd Rasdan Ibrahim, ${ }^{1}$ Herda Yati Katman, ${ }^{1,2}$ Mohamed Rehan Karim, \\ Suhana Koting, ${ }^{1}$ and Nuha S. Mashaan ${ }^{1}$ \\ ${ }^{1}$ Centre for Transportation Research, Faculty of Engineering, University of Malaya, 50603 Kuala Lumpur, Malaysia \\ ${ }^{2}$ Universiti Tenaga Nasional, Putrajaya Campus, Jalan Ikram-Uniten, 43000 Kajang, Selangor, Malaysia
}

Correspondence should be addressed to Mohd Rasdan Ibrahim; rasdan@um.edu.my

Received 31 May 2013; Accepted 11 September 2013

Academic Editor: John W. Gillespie

Copyright (C) 2013 Mohd Rasdan Ibrahim et al. This is an open access article distributed under the Creative Commons Attribution License, which permits unrestricted use, distribution, and reproduction in any medium, provided the original work is properly cited.

\begin{abstract}
Crumb rubber modification has been proven to enhance the properties of pure bitumen. This paper looks at some of the international standards for producing crumb rubber modified bitumen (CRMB) and reviews the effect of crumb rubber to the rheology of crumb rubber modified bitumen. The review shows that the rheology of CRMB depends on internal factors such as crumb rubber quantity, particle size, and pure bitumen composition, and external factors such as the mixing time, temperature, and also the modification technique. These factors govern the swelling process of crumb rubber particles that lead to the increase of viscosity of the modified bitumen. However, the mixing temperature and duration can cause rubber particles to depolymerize and subsequently cause loss of viscosity. Crumb rubber modification also improves the properties of bitumen by increasing the storage and loss modulus and enhancing the high and low temperature susceptibility. The effect of crumb rubber to aging properties of CRMB is also discussed. Finally several techniques of chemical modification to terminal blends of CRMB and the subsequent improvement to the settling property of CRMB are explained.
\end{abstract}

\section{Introduction}

Crumb rubber from waste tyres has been used in pavement construction since the 1930s. The usage has currently increased due the potential it offers in improving the performance of the asphaltic mixes and the potential solution in reducing waste tyres in landfills. Rubber crumbs can be mixed with aggregates within the asphaltic mix (dry process) or blended in bitumen at a specific temperature where rubber crumbs serves as a binder modifier (wet process). Crumb rubber modification by the wet process has been shown to have the ability to help improve the rutting resistance, resilience modulus, and fatigue cracking resistance of asphaltic mixes. This is due to the alteration to the property of the bituminous binder in terms of the viscosity, softening point, [1] loss modulus, and storage modulus [2]. The improvement is governed by the swelling process of rubber particles that interacted with bitumen. Rubber crumbs can swell up to 3 to 5 times its original size due to the absorption of maltenes component of the bitumen $[3,4]$. This left a higher proportion of asphaltenes in the binder, therefore increasing its viscosity. The properties of crumb rubber modified bitumen (CRMB) is very sensitive and are highly governed by the mixing process which is dependent on external factors such as the mixing temperature, mixing duration, and type and internal factors such as type of bitumen, crumb rubber quantity, particle size, and type. Accurate selection of the processing variables is the key to successful CRMB production. Table 1 lists the key parameters in for preparing CRMB that are suggested by American Society of Testing Material (ASTM), California Department of Transportation (Caltrans), South African Bitumen Association (Sabita), and Association of Australian and New Zealand Road Transport and Traffic Authorities (Austroads) [5].

In recent developments, terminal blend CRMB has gained popularity due to a higher quality product $[6,7]$. Unlike conventional wet mix that creates gel-like rubber particles through swelling, terminal blend process uses high 
TABLE 1: Important parameters in manufacturing CRMB according to several specifications around the world (adopted from [5]).

\begin{tabular}{|c|c|c|c|c|}
\hline Properties & ASTM 2002 & Caltrans 2006 & Sabita 2007 & Austroads 2007 \\
\hline Bitumen penetration $(\mathrm{dmm})$ & $\begin{array}{c}\text { Type 1: } 85-100 \\
\text { Type 2: } 120-150 \\
\text { Type 3: } 200-300\end{array}$ & $120-150$ & $60-100$ & $85-100$ \\
\hline Rubber sieve size (mm) & 2.36 & 2.36 & 1.18 & 2.36 \\
\hline Rubber content (\%) & $\geq 15$ & $18-22$ & $18-24$ & $15-18$ \\
\hline Extender oil (\%) & - & $2.5-6$ & $0-4$ & - \\
\hline Calcium carbonate/talc (\%) & $0-4$ & - & $0-4$ & - \\
\hline Mixing temperature $\left({ }^{\circ} \mathrm{C}\right)$ & 177 & $190-220$ & $180-220$ & 195 \\
\hline Mixing speed (rpm) & - & - & 3000 & - \\
\hline Mixing time (min) & $45+$ reaction & $45-60$ & - & $30-45$ \\
\hline
\end{tabular}

shear mechanism to completely depolmerize rubber particles, therefore achieving total digestion of crumb rubber into bitumen. Although the viscosity of such mix is reduced, total digestion of crumb rubber resolves the problem of crumb rubber settlement in CRMB. However, some researches argue that too much digestion can cause CRMB to lose its stiffening and elastic effect on the mix [8], thus eliminating the benefit of rubber modification.

This paper reviews the effect of crumb rubber to the rheology of crumb rubber modified bitumen. The interaction between bitumen and crumb rubber and the factors governing the interaction process such the modification technique, mixing time, temperature, and crumb rubber characteristics are also being discussed along with the properties of the resulting CRMB. This is to give a comprehensive review on the effect of each factor to the property of the resulting crumb rubber modified bitumen.

\section{External Factors}

The mixing temperature and duration of crumb rubber modified bitumen are very crucial and will affect the performance of the binder. Due to the unique and delicate interaction process and the number of parameters involved, it is important that the mixing process of bitumen with rubber is handled with extra precautions and care. For instance, coarser rubber particles and higher rubber concentrations would require a higher mixing temperature where a more stable binder against rubber segregation and settling can be achieved $[6,11]$. However, rubber will be depolymerized and dispersed into the mix if the temperature is too high and the duration is too long [12]. Crumb rubber mesh size, curing time, temperature, and mixing rate are the factors that affect the rubber depolymerisation rate [13]. Table 2 summarises the mixing parameters by some of Transportation Agencies in the United States and Canada.

The rate of swelling and the extent of swelling are highly dependent on the temperature of the interaction process. The rate of swelling increases when the temperature is increased; however, with the increase in temperature, the extent of swelling on the other hand decreases [14]. Lalwani et al. [15] reported that, at lower temperatures, the rubber-asphalt mix is nonhomogenous and has a higher viscosity; however, when the temperature is increased beyond $200^{\circ} \mathrm{C}$, depolymerisation occurs causing undesirable hardening of the binder. Depolymerisation process occurs slowly when the temperature is between $150^{\circ} \mathrm{C}$ and $200^{\circ} \mathrm{C}$ and proceeds rapidly (within several hours) when the temperature is above $200^{\circ} \mathrm{C}$ [16]. Viscosity increases continually at $150^{\circ} \mathrm{C}$ and at $175^{\circ} \mathrm{C}$ or $200^{\circ} \mathrm{C}$, and the viscosity initially increases rapidly, then reduces its pace, and subsequently decreases. At higher temperatures, $\left(225^{\circ} \mathrm{C}\right)$ the viscosity reaches a maximum value within $5 \mathrm{~min}$ and decreases rapidly thereafter [17].

Shen and Amirkhanian [18] concluded that a mixing process for 15 minutes at $177^{\circ} \mathrm{C}$ is adequate for $15 \%$ of rubber crumb addition sizing between 30 and 40 mesh size to fully interact with the binder. Jeong et al. [19] on the other hand concluded that, for a $10 \%$ crumb rubber mixture, a longer blending time up to 60 minutes and mixing temperature up to $177^{\circ} \mathrm{C}$ can contribute to a higher failure temperature and viscosity of binder at $135^{\circ} \mathrm{C}$. However, while releasing harmful gases into the environment, longer mixing duration and higher mixing and storage temperature have been shown to cause a higher rubber particles size reduction which leads to depolymerisation and subsequently leads to loss in viscosity. In an attempt to balance performance and storage compatibility of crumb rubber modified bitumen, Attia and Abdelrahman [6] suggested the use of fine rubber crumb to produce terminal blends of CRM. This approach saves energy as only $8 \%$ of the total interaction time requires high temperature of $200^{\circ} \mathrm{C}$ and lower temperature can be used for the storage period. Billiter et al. [7] also suggested that by increasing the mixing temperature, mixing time and shear rate can be reduced and this can in fact produce a homogenous and truly elastic terminal blend that have an enhanced performance.

At higher temperatures, the viscosity of CRMB was found to increase quite dramatically. According to Jeong et al. [19] compared to binder that was mixed at $177^{\circ} \mathrm{C}$, at $200^{\circ} \mathrm{C}$ the viscosity is $5 \%$ higher, and at $223^{\circ} \mathrm{C}$ the viscosity increased $41 \%$. With regards of the blending time, it was found that the viscosity of binder that was mixed for 5 minutes increases $11 \%$, while at 480 minutes the viscosity increased to $46 \%$. On the other hand, the failure temperature between binder mixed at $177^{\circ} \mathrm{C}$ and $200^{\circ} \mathrm{C}$ was found to be negligible. 
TABle 2: Mixing parameters used by several Transportation Agencies (adopted from [9]).

\begin{tabular}{|c|c|c|c|c|}
\hline Agency & $\begin{array}{c}\text { Mixing } \\
\text { temperature }\end{array}$ & $\begin{array}{l}\text { Mixing time } \\
\quad(\min )\end{array}$ & Crumb rubber size & Crumb rubber (\%) \\
\hline Ontario, Canada & $180^{\circ} \mathrm{C}$ & 45 & $\begin{array}{c}0.5 \mathrm{~mm} \text { to } 1.0 \mathrm{~mm} \text {. Gradation should be } \\
\text { suitable to Type III of ASTM. }\end{array}$ & $18-20 \%$ \\
\hline \multirow[t]{2}{*}{ California } & $\begin{array}{l}190-226^{\circ} \mathrm{C} \\
\text { (adding CR) }\end{array}$ & \multirow[t]{2}{*}{45 (minimum) } & \multirow[t]{2}{*}{$\begin{array}{c}2.36 \mathrm{~mm}-75 \mu \mathrm{m} \text {. Length of particle should not } \\
\text { exceed } 4.75 \mathrm{~mm}\end{array}$} & \multirow{2}{*}{$\begin{array}{l}20 \pm 2 \% ;(75 \% \text { scrap } \\
\text { tire CR and } 25 \% \text { high } \\
\text { natural CR })\end{array}$} \\
\hline & $\begin{array}{l}190-218^{\circ} \mathrm{C} \\
\text { (blending) }\end{array}$ & & & \\
\hline \multirow[t]{2}{*}{ Arizona } & $\begin{array}{l}180-205^{\circ} \mathrm{C} \\
\text { (adding CR) }\end{array}$ & 60 (minimum) & \multirow[t]{2}{*}{$\begin{array}{c}\text { Type A (for chip seals): } 2.36 \mathrm{~mm}-1.18 \mathrm{~mm} \\
\text { Type B: } 2.0 \mathrm{~mm}-75 \mu \mathrm{m}\end{array}$} & \multirow[t]{2}{*}{ Minimum 20\% } \\
\hline & $\begin{array}{l}165-190^{\circ} \mathrm{C} \\
\text { (blending) }\end{array}$ & & & \\
\hline Florida & $168-190^{\circ} \mathrm{C}$ & 30 (minimum) & $\begin{array}{l}\text { Type A: } 150 \mu \mathrm{m}-300 \mu \mathrm{m} \\
\text { Type B: } 300 \mu \mathrm{m}-600 \mu \mathrm{m} \\
\text { Type C: } 1.18 \mathrm{~mm}-300 \mu \mathrm{m}\end{array}$ & Minimum 20\% \\
\hline
\end{tabular}

TABle 3: Properties of crumb rubber modified bitumen (adopted from [10]).

\begin{tabular}{|c|c|c|c|c|c|c|c|}
\hline \multirow{2}{*}{ Binder property } & \multicolumn{7}{|c|}{ Percent of rubber (by weight of binder) } \\
\hline & 0 & 6 & 9 & 12 & 15 & 18 & 21 \\
\hline Viscosity at $176^{\circ} \mathrm{C}(\mathrm{cP})$ (ASTM D2669) & 60 & 550 & 800 & 900 & 1500 & 2500 & 6000 \\
\hline Cone penetration in $0.1 \mathrm{~mm}, 150 \mathrm{~g}, 5$ seconds at $25^{\circ} \mathrm{C}$ (ASTM D5329) & 48 & 40 & 43 & 44 & 40 & 30 & 27 \\
\hline Resilience (\%) at $25^{\circ} \mathrm{C}$ (ASTM D5329) & -1 & -1 & 12 & 19 & 23 & 40 & 47 \\
\hline Softening point, ${ }^{\circ} \mathrm{C}$ (ASTM D36) & 50 & 52 & 58 & 60 & 61 & 63 & 72 \\
\hline
\end{tabular}

However, the failure temperature increased with blending time up to 60 minutes. Beyond the 60 minute period, the fail temperature was found not to be affected by blending time.

Mixing type too can affect the properties of crumb rubber modified bitumen. Low temperature properties, for instance, were improved with high shear mixing, while low shear mixing improves medium and high temperature properties and its resistance to fatigue cracking [20]. Dynamic viscosity, however, is not affected by blending type [21]. For high shear mixing technique, to produce optimal results for softening point and penetration values for modified binder with less than $25 \%$ crumb rubber, Li et al. had suggested a shearing time of $40 \mathrm{~min}$ and a shearing temperature of $180^{\circ} \mathrm{C}$ with a shearing rotational speed of $7000 \mathrm{rpm}$. High shear mixing will reduce the size of coarser rubber, thus speeding the interaction process. Storage stability and rubber particle dispersal can also be improved with high speed shear mixing. Attia and Abdelrahman [6] had proven that $88 \%(0.6 \%$ remaining from $5 \%$ rubber by the weight of bitumen) of the rubber particle can be digested by the end of the interaction process. The shape of the impeller, on the other hand, does not contribute to any changes to the rheology of binders [11]. Celauro et al. [22], however, mentioned that a low shear mixing can also produce the best performing CRMB provided that the base bitumen and crumb rubber are appropriately selected.

\section{Internal Factor: Crumb Rubber Quantity and Type of Bitumen}

The addition of crumb rubber has been shown to increase the properties of the bitumen such as the softening point, penetration, and the viscosity in proportion of the amount of the rubber $[10,19,23,24]$. Table 3 shows the properties of AC-20 asphalt blended with up to $21 \%$ of $1.18 \mathrm{~mm}$ whole tire crumb rubber size with mixing time of 90 minutes at $176^{\circ} \mathrm{C}$. Bitumen with higher viscosity will generally have a higher failure temperature and therefore have a longer service life due to higher temperature stability. Comparing crumb rubber addition of $10 \%$ and $20 \%$, Jeong et al. [19] show that the $20 \%$ crumb rubber addition increased the viscosity by $550 \%$ and $G^{*} / \sin \delta$ (stiffness) value by $225 \%$. However, when subjected to Rolling Thin Film Oven test (RTFOT) which simulated short-term aging, it is found that the viscosity decreases with increasing rubber concentration [23]. This is probably due to higher rubber dissolution as demonstrated by Billiter et al. [7].

Apart from increasing the viscosity at high temperature, crumb rubber also contributes to a lower creep stiffness of the asphaltic mix which increases the low temperature cracking resistance of asphaltic pavement and lowering the aging index [23-26]. Wang et al. [23] recommended $15 \%$ to $20 \%$ crumb rubber addition for a significant improvement in aging effects, creep stiffness, and economic factors. Shen and Amirkhanian [18] on the other hand showed that $10 \%$ of 
TABLE 4: Chemical composition of various types of tires (adopted from [10]).

\begin{tabular}{|c|c|c|c|c|}
\hline Chemical composition & Passenger/light truck tread rubber (\%) & Heavy truck tread rubber $(\%)$ & Whole tire rubber $(\%)$ & Range (\%) \\
\hline Acetone extract & 17.2 & 11.4 & 15.1 & 5.8 \\
\hline Ash & 4.8 & 5.1 & 5.0 & 0.29 \\
\hline Carbon black & 32.7 & 33.2 & 32.0 & 1.2 \\
\hline Rubber hydrocarbon & 42.9 & 50.2 & 47.9 & 7.3 \\
\hline
\end{tabular}

CRM addition increased the performance grade of bitumen from $64^{\circ} \mathrm{C}$ to $70^{\circ} \mathrm{C}$ and $15 \% \mathrm{CRM}$ addition increased at least two high temperature performance grades from $64^{\circ} \mathrm{C}$ to $76^{\circ} \mathrm{C}$. However, Khalid and Artamendi [27] highlight that an addition of crumb rubber of more than $10 \%$ would produce a binder that is too viscous for field mixing operations.

Crumb rubber modified bitumen, however, can have storage problems due the settling of the rubber crumbs. Shearing the mix in high temperature until the rubber particles depolymerize is one of the options that can eliminate sedimentation problems and subsequently improve the properties of the bitumen if properly manufactured [6]. Very fine rubber particles (100 to 500 mesh) on the other hand have nonsettling properties when processed with high shear mixing. This can reduce the mixing time and temperature and therefore reduce depolymerisation and enhance aging resistance [25]. Cong et al. [28] showed that a high amount of rubber (e.g., 25\%), with a high swelling rate and a high lightweight fraction bitumen can improve the storage stability of CRMB. This is due to the reduction of the nondissolved rubber particle, thus reducing the sedimentation trend of the rubber particles. Navarro et al. [29] on the other hand reported that crumb rubber modified bitumen is stable for particles that are sized $0.29 \mathrm{~mm}$ or less.

Crumb rubber from waste tyres typically contains several types of compounds such as synthetic rubber content, natural rubber content, total rubber hydrocarbon content, and acetone extractables [10]. This is due to the different proportion of natural rubber, synthetic rubber, and other components between truck tyres and passenger car tyres. For instance, truck tyres contain more natural rubber when compared to passenger cars (which is higher in synthetic rubber) and this can affect the interaction between bitumen and rubber particles. Higher dissolution of crumb rubber that contains a mixture of truck and passenger car tyres can improve the viscoelastic properties of bitumen, while higher dissolution of crumb rubber solely sourced from truck tyres does not enhance the properties of the modified binder [30]. Table 4 shows the chemical composition of passenger car tire and truck tires [10]. Thodesen et al. [31], however, showed that CRMB produced using truck tire crumb poses the highest viscosity, and Cao and Bai [32] reported that crumb rubber that comes from truck tires gives a better performance in terms of a better fatigue resistance and high temperature performance.

The properties of pure bitumen used to produce CRMB also are very important to the quality of the modified binder. Softer bitumen with higher lightweight fraction gives a higher swelling rate to the rubber particles and thus displays a better high and low temperature properties compared to harder bitumen with the same amount of rubber modification $[12,28]$. Stiffer bitumen will typically show better high temperature stiffness compared to CRMB produced with softer bitumen that have improved low temperature stiffness. Bitumen with a lower lightweight fraction will also produce CRMB that has lower viscosities and lesser degree of modification properties [10].

Ould Henia and Dumont [33] studied the effect of pure bitumen with different composition of saturates, aromatics, resin, and asphaltenes to the viscoelastic properties and the extent of crumb rubber swelling in CRMB. The study shows that aromatic oils perform as lubricant for asphaltenes, hence bitumen with higher aromatic content has a higher viscosity and displays a higher sensitivity to temperature than harder bitumen. The quantity of aromatics in the bitumen is also important to be determined prior to the mixing process in order to obtain the optimum amount of swelling in the rubber particles and subsequently ensuring the consistency of the physical properties of the mix.

\section{Internal Factor: Crumb Rubber Type and Particle Size}

Crumb rubber sizes can be classified into four groups, which are coarse $(9.5 \mathrm{~mm}$ and $6.3 \mathrm{~mm})$; medium size (10-30 mesh or $2 \mathrm{~mm}$ to $600 \mu \mathrm{m})$; fine $(40-80$ mesh or $425 \mu \mathrm{m}$ to $180 \mu \mathrm{m})$; and superfine (100-200 mesh or $150 \mu \mathrm{m}$ to $75 \mu \mathrm{m})$ [34]. Similar to mixing time and temperature, crumb rubber mesh size is one of the important factors that govern the rubber depolymerization rate [35]. Finer crumb rubber will swell faster due to a larger specific area and therefore gives higher viscosities compared to coarser size. CRMB produced from fine rubber particles will also have a faster viscosity reduction in the heating process due to its faster swelling rate and thus a faster depolymerisation process. Sun and Li mentioned that the factors that influence the viscosity of CRMA according to their order of significance are crumb rubber content, mixing temperature, rubber particle size, and mixing time $[17,36]$.

Apart from its sizing, crumb rubber properties can also differ in terms of its microstructure. Several methods have been used to improve the microstructure of crumb rubber surface. Microwave irradiation of crumb rubber surface method cleft the surface of the vulcanization network, giving crumb rubber higher surface activity, and therefore improves its viscoelastic nature and storage stability [37]. Shatanawi et al. [38] explore the possibility of using hot water to activate the surfaces of crumb rubber. This process removes light oil fractions in the crumb rubber particles, where it 
reduces segregation between rubber particles and binder, thus improving its compatibility. Although the process does improve the settling properties of CRMB, it does not improve the rheology of the binder.

The difference in the crumb rubber surface microstructure can also differ due to the method the crumb rubber is manufactured. Rubber crumbs that are produced using the cryogenic method have angular, smooth, and cracked appearance, while crumbs that were produced using ambient grinding have a rather porous surface [18]. This gives the crumb rubber that was produced using the ambient grinding twice the amount of surface area when compared with its cryogenic counterpart [39].

Due to its larger surface area and subsequent swelling rate, ambient processed crumb rubber will generally give a better performance than its cryogenic counterpart [28]. CRMB produced from ambient crumb rubber gives a higher viscosity, complex modulus, and phase angle and thus gives better rutting resistance and higher elasticity [39-42]. Porous surface of ambient crumb rubber assisted the absorption of higher light constituents from the asphalt, thus increasing its failure temperature regardless of the mixing time. Lee et al. [41] showed that CRM binders produced with ambient CRM also showed a better resistance on low temperature cracking than those with cryogenic CRM.

Crumb rubber particle size also plays an important role in determining the outcome performance of CRMB. Smaller particle size produces modified bitumen that has higher viscosity, softening point, and resilience due to a higher surface area [17, 25, 43, 44] and aspect ratio [45]. Wang et al. [23] reported that finer crumb rubber attains higher viscosity at high temperature and lower creep stiffness at low temperature. Higher viscosity also leads to a better rutting resistance as shown by C. C. Wong and W.-g. Wong [46]. Cao and Bai [32] on the other hand showed that larger crumb rubber gives a better high temperature performance and similar low temperature cracking resistance between CRMB manufactured with smaller crumb rubber particle size.

Similar results are demonstrated by Sebaaly et al. [26] where the authors mentioned that while crumb rubber size does not have a significant effect on the low temperature properties of bitumen, different combinations of crumb rubber size and content can either improve or jeopardize the low temperature performance grade of the CRMB. A separate design of optimum rubber content is therefore required for each crumb rubber size and bitumen grade to ensure a properly designed CRMB.

Attia and Abdelrahman [6] and Navarro et al. [45] focused on a wide variety of crumb rubber sizes in their attempt to study the effect of crumb rubber particle size to the rheology of bitumen. Their study concluded that the incorporation of coarser rubber into bitumen increases the $G^{*}$ value [6] and subsequently increases the value of storage $\left(G^{*} / \sin \delta\right)$ and loss moduli $\left(G^{*} \sin \delta\right)$ especially at low frequencies. However, according to Tayebali et al. [47], the coefficient of variance for the $G^{*} / \sin \delta$ values obtained from samples modified with 40 mesh crumb rubber size is statistically in close approximate with the one modified with an 80 mesh crumb rubber. Liu et al. [36] also mentioned that there is no significant difference between basic performances of bitumen modified with different crumb rubber size. However, it is important to note that in this particular research, the crumb rubber sizes used are 60 mesh and 80 mesh size which is rather closely spaced.

\section{Aging Properties of CRMB}

Binder aging is a process of oxidation and loss of lightweight constituents in bitumen that leads to hardening of the material. There are two types of aging, namely, short-term aging and long-term aging. Short-term aging occurs during the mixing period of aggregate and bitumen, while long-term aging occurs in a longer time period after the construction process. In the oxidation process, polar aromatics component of the bitumen is converted into asphaltenes, and this can be indicated by carbonyl formation [48] and resulted in a binder that has a higher viscosity. For this reason, it is important that the selection of pure bitumen to produce CRMB is done correctly since the short-term aging of CRMB manufactured using harder bitumen can create a binder that is too hard and cannot be used for paving applications [49].

Rubber addition can help to reduce the hardening rate and susceptibility of bitumen [49-51]. Rubber also helps in lowering viscosity buildup with aging at low temperatures [52]. Gel permeation chromatography analysis shows that a higher proportion of crumb rubber (15\% to $20 \%$ ) in the bitumen contributes to the reduction of large molecular size value of the binder. This is due to the ejection of lighter constituents that were earlier absorbed by the rubber from the bitumen [53]. This helps in reducing the rate of asphaltenes formation, therefore slowing the aging process [51]. In order to further improve the aging characteristics of CRMB, Chipps et al. recommend the use of low-asphaltene bitumen processed with high-cure (terminal blend) CRMB with minimum rubber content of 10\% [48]. Although hardening of asphalt cannot be avoided, there are ways that aged bitumen can be rejuvenated to its original properties with the help of rejuvenating agent [54] or other substance such as recycled waste cooking oil [55]. This technology has the potential to be an excellent solution in using recycled asphaltic pavement.

\section{Chemical Modification of CRMB}

Chemical modification of CRMB aims to alter the typical chemical bonding between bitumen and rubber particles. This is typically achieved with terminal blending process enhanced with certain chemicals or activators. Kocevski et al. [56] use grafting process to improve the properties of CRMB. In this process, the surface of crumb rubber is modified by bulk polymerization of acrylic acid. This process also can increase the viscosity and failure temperature of the CRMB. Chemical modifications that generate free radicals on the surface of crumb rubber are used by the US Federal Highway Administration where better interactions with bitumen are achieved resulting in a homogenous CRMB mix, therefore improving storage stability of the mix [57]. 
Yadollahi and Sabbagh Mollahosseini [58] on the other hand uses polyphosphoric acid and an additive known as Vestenamer to achieve crosslinking between the sulphur elements in the asphaltenes and maltenes in the bitumen to produce macropolymer network. This produces a CRMB that has better elastic properties at high temperatures and lower creep stiffness at low temperatures. Shatanawi et al. [59] showed that storage stability of CRMB can be highly improved with the addition of furfural as an activation agent in the mix. Better storage stability is also achieved by Cheng et al. [60] that uses polymeric compatibilizer containing conjugated diene that reacts as a crosslinking agent. In addition to that, the CRMB produced also has an improved permanent deformation and thermal cracking resistance.

\section{Conclusion}

Crumb rubber modifications of bitumen have been proven to improve characteristics of bituminous binder such as the viscosity, softening point, loss modulus, and storage modulus. This subsequently improves the rutting resistance, resilience, and improving fatigue cracking resistance of asphaltic mixes. In order to achieve a superior and balanced CRMB in term of high and low temperature properties, factors such as the mixing time, temperature, characteristics, and source of the crumb rubber and bitumen type must be considered since these are the factors that govern the resulting performance of asphaltic mixes. Aging mechanism of CRMB is also important to be considered in order that the resulting CRMB has a workable viscosity to be applied in the construction process. Finally, chemical modification of CRMB is a new area that has promising possibilities in the future to further enhance the properties of CRMB and at the same time eliminate rubber particle settling problem that is one of the limiting factor in the current application of crumb rubber modified bitumen.

\section{Conflict of Interests}

The authors declare that there is no conflict of interests regarding the publication of this paper.

\section{References}

[1] J. L. McQuillen, H. B. Takallou, R. Gary Hicks, and D. Esch, "Economic analysis of rubber-modified asphalt mixes," Journal of Transportation Engineering, vol. 114, no. 3, pp. 259-277, 1988.

[2] A. H. Ali, N. S. Mashaan, and M. R. Karim, "Investigations of physical and rheological properties of aged rubberised bitumen," Advances in Materials Science and Engineering, vol. 2013, Article ID 239036, 7 pages, 2013.

[3] J. Peralta, H. M. R. D. Silva, A. V. Machado, J. Pais, P. A. A. Pereira, and J. B. Sousa, "Changes in rubber due to its interaction with bitumen when producing asphalt rubber," Road Materials and Pavement Design, vol. 11, no. 4, pp. 1009-1031, 2010.

[4] W. C. Vonk and A. L. Bull, "Phase phenomena and concentration effects in blends of bitumen and cariflex TR," in Proceedings of the 7th International Roofing Congress, Munich, Germany, 1989.
[5] D. Lo Presti, G. Airey, and P. Partal, "Manufacturing terminal and field bitumen-tyre rubber blends: the importance of processing conditions," Procedia, vol. 53, pp. 485-494, 2012.

[6] M. Attia and M. Abdelrahman, "Enhancing the performance of crumb rubber-modified binders through varying the interaction conditions," International Journal of Pavement Engineering, vol. 10, no. 6, pp. 423-434, 2009.

[7] T. C. Billiter, J. S. Chun, R. R. Davison, C. J. Glover, and J. A. Bullin, "Investigation of the curing variables of asphalt rubber binder," Petroleum Science and Technology, vol. 15, no. 5-6, pp. 445-469, 1997.

[8] "The Effects of digesting Crumb Rubber in Modified Binders," The University of Wisconsin-Madison Asphalt Research Group in collaboration with the Recycled Materials Resource Center, pp. 1-13, 2011.

[9] D. X. Cheng and R. G. Hicks, "Summary of Rubber Modified Asphalt Product Specifications from around the World," Ontario Tire Stewardship, pp. 1-218, 2012.

[10] "Crumb rubber modifier design procedures and construction practices," Workshop Notes FHWA-SA-93-011, Design procedure and construction practices, US Department of Transportation, Federal Highway Administration, 1993.

[11] F. J. Navarro, P. Partal, F. J. Martínez-Boza, and C. Gallegos, "Influence of processing conditions on the rheological behavior of crumb tire rubber-modified bitumen," Journal of Applied Polymer Science, vol. 104, no. 3, pp. 1683-1691, 2007.

[12] J. G. Chehovits, "Design Methods for Hot Mix Asphalt-Rubber Concrete Paving Materials," presented at the National Seminar on Asphalt-Rubber, 1989.

[13] L. F. M. Leite, R. S. Constantino, and A. Vivoni, "Rheological studies of asphalt with ground tire rubber," Road Materials and Pavement Design, vol. 2, no. 2, pp. 125-139, 2001.

[14] E. L. Green and W. J. Tolonen, "The chemical and physical properties of asphalt-rubber mixtures," Tech. Rep. ADOT-RS14 (162), Arizona Department of Transportation, 1977.

[15] S. Lalwani, A. Abushihada, and A. Halasa, "Reclaimed rubberasphalt blends measurement of rheological properties to assess toughness, resiliency, consistency and temperature sensitivity," Journal of the Association of Asphalt Paving Technologists, vol. 51, pp. 562-579, 1982.

[16] H. B. Takallou, Mix Design Guidelines for Rubber Modified Asphalt Concrete, Tak Associates, Portland, Ore, USA, 1991.

[17] D. Q. Sun and L. H. Li, "Factors affecting the viscosity of crumb rubber-modified asphalt," Petroleum Science and Technology, vol. 28, no. 15, pp. 1555-1566, 2010.

[18] J. Shen and S. Amirkhanian, "The influence of crumb rubber modifier (CRM) microstructures on the high temperature properties of CRM binders," The International Journal of Pavement Engineering, vol. 6, no. 4, pp. 265-271, 2005.

[19] K. D. Jeong, S. J. Lee, S. N. Amirkhanian, and K. W. Kim, "Interaction effects of crumb rubber modified asphalt binders," Construction and Building Materials, vol. 24, no. 5, pp. 824-831, 2010.

[20] S. Aflaki and M. Memarzadeh, "Using two-way ANOVA and hypothesis test in evaluating crumb rubber modification (CRM) agitation effects on rheological properties of bitumen," Construction and Building Materials, vol. 25, no. 4, pp. 20942106, 2011.

[21] H. Li, H. Zhao, and K. Liao, "Study on the technological conditions of crumb tire rubber-modified bitumens," Petroleum Science and Technology, vol. 27, no. 14, pp. 1521-1533, 2009. 
[22] B. Celauro, C. Celauro, D. Lo Presti, and A. Bevilacqua, "Definition of a laboratory optimization protocol for road bitumen improved with recycled tire rubber," Construction and Building Materials, vol. 37, pp. 562-572, 2012.

[23] H. Wang, Z. You, J. Mills-Beale, and P. Hao, "Laboratory evaluation on high temperature viscosity and low temperature stiffness of asphalt binder with high percent scrap tire rubber," Construction and Building Materials, vol. 26, no. 1, pp. 583-590, 2012.

[24] F. M. Nejad, P. Aghajani, A. Modarres, and H. Firoozifar, "Investigating the properties of crumb rubber modified bitumen using classic and SHRP testing methods," Construction and Building Materials, vol. 26, no. 1, pp. 481-489, 2012.

[25] T. C. Billiter, R. R. Davison, C. J. Glover, and J. A. Bullin, "Physical properties of asphalt-rubber binder," Petroleum Science and Technology, vol. 15, no. 3-4, pp. 205-236, 1997.

[26] P. E. Sebaaly, V. T. Gopal, and J. A. Epps, "Low temperature properties of crumb rubber modified binders," Road Materials and Pavement Design, vol. 4, no. 1, pp. 29-49, 2003.

[27] H. A. Khalid and I. Artamendi, "Performance based characterisation of crumb rubber asphalt modified using the wet process," Road Materials and Pavement Design, vol. 4, no. 4, pp. 385-399, 2003.

[28] P. Cong, P. Xun, M. Xing, and S. Chen, "Investigation of asphalt binder containing various crumb rubbers and asphalts," Construction and Building Materials, vol. 40, pp. 632-641, 2013.

[29] F. J. Navarro, P. Partal, F. Martínez-Boza, and C. Gallegos, "Thermo-rheological behaviour and storage stability of ground tire rubber-modified bitumens," Fuel, vol. 83, no. 14-15, pp. 2041-2049, 2004.

[30] A. Ghavibazoo and M. Abdelrahman, "Composition analysis of crumb rubber during interaction with asphalt and effect on properties of binder," International Journal of Pavement Engineering, vol. 14, no. 5, pp. 517-530, 2012.

[31] C. Thodesen, K. Shatanawi, and S. Amirkhanian, "Effect of crumb rubber characteristics on crumb rubber modified (CRM) binder viscosity," Construction and Building Materials, vol. 23, no. 1, pp. 295-303, 2009.

[32] R. Cao and Q. Bai, "Laboratory evaluation of performances of asphalt rubber and gap graded mixtures," in Proceedings of the 7th International Conference of Chinese Transportation Professionals Congress: Plan, Build, and Manage Transportation Infrastructures in China (ISSTP '07), pp. 786-798, May 2007.

[33] M. Ould Henia and A.-G. Dumont, "Effect of base bitumen composition on asphalt rubber binder properties," in Proceedings of the International Symposium on Asphalt Pavement and Environment (ISAP '08), pp. 21-30, Zürich, Switzerland, August 2008.

[34] N. Sunthonpagasit and M. R. Duffey, "Scrap tires to crumb rubber: feasibility analysis for processing facilities," Resources, Conservation and Recycling, vol. 40, no. 4, pp. 281-299, 2004.

[35] L. F. M. Leite and B. G. Soares, "Interaction of asphalt with ground tire rubber," Petroleum Science and Technology, vol. 17, no. 9-10, pp. 1071-1088, 1999.

[36] S. Liu, W. Cao, J. Fang, and S. Shang, "Variance analysis and performance evaluation of different crumb rubber modified (CRM) asphalt," Construction and Building Materials, vol. 23, no. 7, pp. 2701-2708, 2009.

[37] G.-X. Yu, Z.-M. Li, X.-L. Zhou, and C.-L. Li, "Crumb rubbermodified asphalt: microwave treatment effects," Petroleum Science and Technology, vol. 29, no. 4, pp. 411-417, 2011.
[38] K. Shatanawi, S. Biro, C. Thodesen, and S. Amirkhanian, "Effects of water activation of crumb rubber on the properties of crumb rubber-modified binders," International Journal of Pavement Engineering, vol. 10, no. 4, pp. 289-297, 2009.

[39] J. Shen, S. Amirkhanian, F. Xiao, and B. Tang, "Influence of surface area and size of crumb rubber on high temperature properties of crumb rubber modified binders," Construction and Building Materials, vol. 23, no. 1, pp. 304-310, 2009.

[40] C. Thodesen, K. Shatanawi, S. Amirkhanian, and W. Bridges, "Development of an empirical model for determining $G^{*} / \sin \delta$ in crumb rubber modified binders," Construction and Building Materials, vol. 23, no. 5, pp. 1922-1927, 2009.

[41] S.-J. Lee, C. K. Akisetty, and S. N. Amirkhanian, "The effect of crumb rubber modifier (CRM) on the performance properties of rubberized binders in HMA pavements," Construction and Building Materials, vol. 22, no. 7, pp. 1368-1376, 2008.

[42] K. M. Shatanawi, C. C. Thodesen, and S. N. Amirkhanian, "Effects of crumb rubber variability on failure temperature of crumb rubber modified binders," Road Materials and Pavement Design, vol. 9, no. 2, pp. 291-309, 2008.

[43] S. A. D. Neto, M. M. Farias, J. C. Pais, and P. A. A. Pereira, "Influence of crumb rubber gradation on asphalt-rubber properties," in Proceedings of Asphalt Rubber Conference, pp. 2-14, Palm Springs, Calif, USA, 2006.

[44] B. J. Putman and S. N. Amirkhanian, "Crumb rubber modification of binders: interaction and particle effects," Road Materials and Pavement Design, vol. 10, no. 10, pp. 1-23, 2006.

[45] F. J. Navarro, P. Partal, F. Martínez-Boza, C. Valencia, and C. Gallegos, "Rheological characteristics of ground tire rubbermodified bitumens," Chemical Engineering Journal, vol. 89, no. $1-3$, pp. 53-61, 2002.

[46] C. C. Wong and W.-g. Wong, "Effect of crumb rubber modifiers on high temperature susceptibility of wearing course mixtures," Construction and Building Materials, vol. 21, no. 8, pp. 1741-1745, 2007.

[47] A. A. Tayebali, B. B. Vyas, and G. A. Malpass, "Effect of crumb rubber particle size and concentration on performance grading of rubber modified asphalt binders," in Progress of Superpave (Superior Performing Asphalt Pavement): Evaluation and Implementation, R. N. Jester, Ed., ASTM STP1322, American Society of Testing and Materials,, 1997.

[48] J. F. Chipps, R. R. Davison, and C. J. Glover, "A model for oxidative aging of rubber-modified asphalts and implications to performance analysis," Energy \& Fuels, vol. 15, no. 3, pp. 637647, 2001.

[49] B. Ali and M. Sadek, "Experimental analysis of the influence of crumb rubber addition on the short-term aging of Syrian asphalt," Arabian Journal of Geosciences, vol. 6, no. 1, pp. 85-90, 2013.

[50] Y. Ruan, R. R. Davison, and C. J. Glover, "Oxidation and viscosity hardening of polymer-modified asphalts," Energy \& Fuels, vol. 17, no. 4, pp. 991-998, 2003.

[51] C. Fanga, C. Wua, R. Yua, Z. Zhangb, M. Zhanga, and S. Zhoua, "Aging properties and mechanism of the modified asphalt by packaging waste polyethylene and waste rubber powder," Polymers for Advanced Technologies, vol. 24, no. 1, pp. 51-55, 2013.

[52] S. C. Huang, "Rheological characteristics of crumb rubbermodified asphalts with long-term aging," Road Materials and Pavement Design, vol. 7, supplement 1, pp. 37-56, 2006.

[53] S.-J. Lee, J. Hu, H. Kim, S. N. Amirkhanian, and K.-D. Jeong, "Aging analysis of rubberized asphalt binders and mixes using 
gel permeation chromatography," Construction and Building Materials, vol. 25, no. 3, pp. 1485-1490, 2011.

[54] J. Shen, S. Amirkhanian, and S. J. Lee, "The effects of rejuvenating agents on recycled aged CRM binders," International Journal of Pavement Engineering, vol. 6, no. 4, pp. 273-279, 2005.

[55] H. Asli, E. Ahmadinia, M. Zargar, and M. R. Karim, "Investigation on physical properties of waste cooking oil-rejuvenated bitumen binder," Construction and Building Materials, vol. 37, pp. 398-405, 2012.

[56] S. Kocevski, S. Yagneswaran, F. Xiao, V. S. Punith, D. W. Smith Jr., and S. Amirkhanian, "Surface modified ground rubber tire by grafting acrylic acid for paving applications," Construction and Building Materials, vol. 34, no. 3, pp. 83-90, 2012.

[57] M. A. Mull, K. Stuart, and A. Yehia, "Fracture resistance characterization of chemically modified crumb rubber asphalt pavement," Journal of Materials Science, vol. 37, no. 3, pp. 557566, 2002.

[58] G. Yadollahi and H. Sabbagh Mollahosseini, "Improving the performance of crumb rubber bitumen by means of poly phosphoric acid (PPA) and vestenamer additives," Construction and Building Materials, vol. 25, no. 7, pp. 3108-3116, 2011.

[59] K. M. Shatanawi, S. Biro, A. Geiger, and S. N. Amirkhanian, "Effects of furfural activated crumb rubber on the properties of rubberized asphalt," Construction and Building Materials, vol. 28, no. 1, pp. 96-103, 2012.

[60] G. Cheng, B. Shen, and J. Zhang, "A study on the performance and storage stability of crumb rubber-modified asphalts," Petroleum Science and Technology, vol. 29, no. 2, pp. 192-200, 2011. 

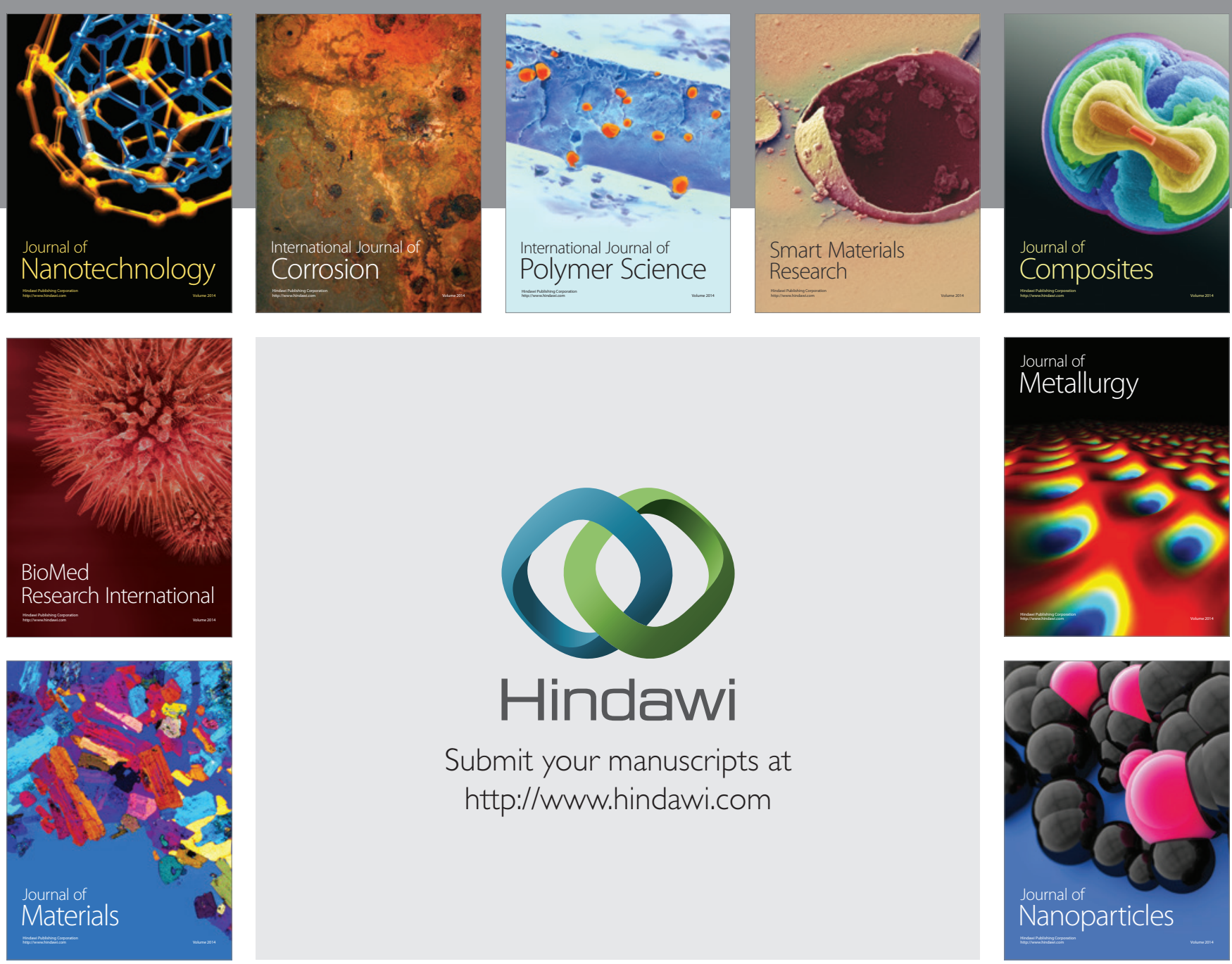

Submit your manuscripts at http://www.hindawi.com
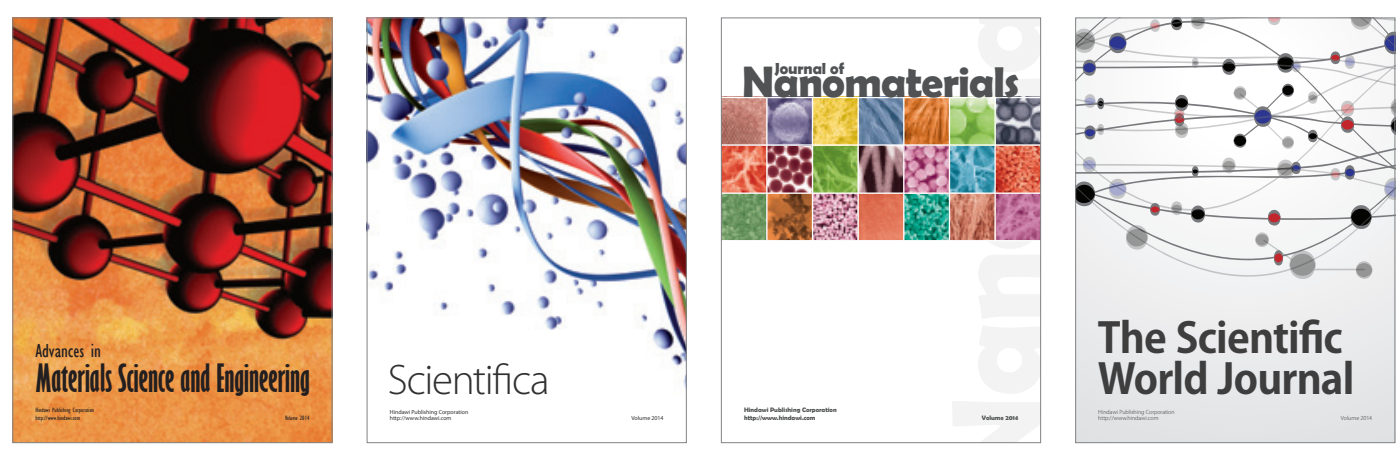

\section{The Scientific World Journal}
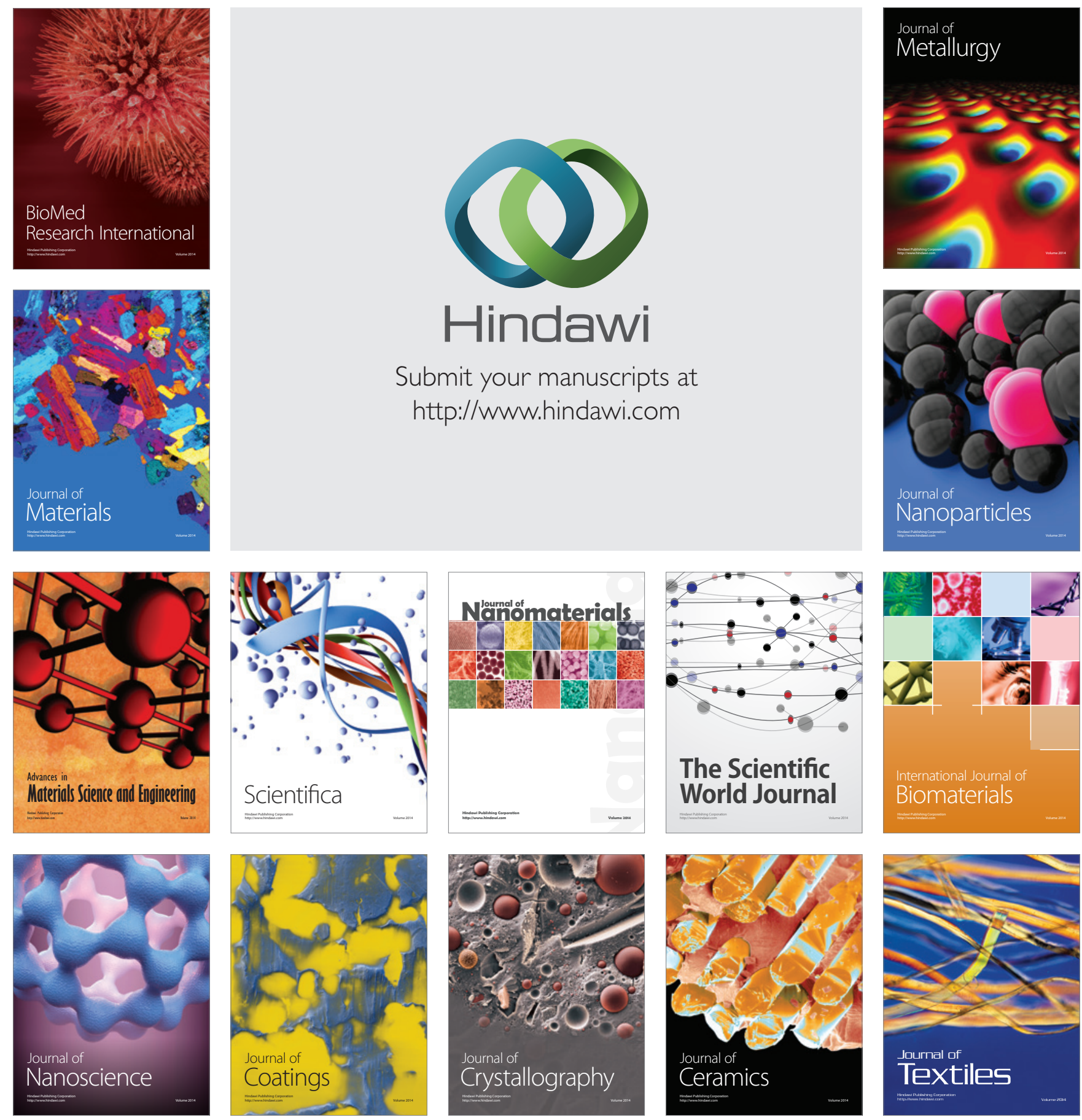